\title{
Relationship of Fat Distribution With Adipokines in Patients With Acquired Immunodeficiency Virus Infection
}

\author{
Daniel A. de Luis, ${ }^{*}$ Pablo Bachiller, Teresa Palacios, Rosa Conde, Olatz Izaola, \\ Beatriz de la Fuente, and Jose M. Eiros Bouza \\ Facultad de Medicina, Centro de Investigacion en Endocrinologia y Nutricion Clinica (I.E.N), Unit of \\ Investigation Hospital Universitario Rio Hortega, Valladolid, Spain
}

\begin{abstract}
Background: The aim was to examine the relationship of fat distributions with adipokines concentrations in HIV-infected patients. Methods: This was a crosssectional analysis of 36 HIV (free of lipodystrophy) infected patients. Dual-energy $X$ ray absorptiometry was used. Results: In the multivariate analysis, basal adiponectin concentration was a dependent variable, whereas waist to hip ratio and abdominal fat mass were independent predictors in the model $(F=5.1 ; P<0.05)$. Adiponectin concentration decreases by $5.541 .2 \mu \mathrm{g} / \mathrm{ml}$ (Cl 95\%: 8,071.9-3,029.1) for each unit of waist to hip ratio and 561.9
\end{abstract}

Key words: adipokines; fat distribution; HIV $\mathrm{ng} / \mathrm{ml} \mathrm{(Cl} \mathrm{95 \% :} \mathrm{918.2-213.4)} \mathrm{for} \mathrm{each}$ kilogram of fat mass of abdominal area. In the multivariate analysis, basal leptin concentration was a dependent variable, whereas waist circumference remained an independent predictor in the model $(F=6.3 ; P<0.05)$, with a direct correlation. Leptin concentration increases by $0.067 \mathrm{ng} / \mathrm{ml} \mathrm{(Cl} \mathrm{95 \% :} \mathrm{0.001-0.12)}$ for each centimeter of waist circumference. Conclusions: Leptin and adiponectin are related with adiposity in HIVinfected patients. J. Clin. Lab. Anal. 26:336341, 2012. (c) 2012 Wiley Periodicals, Inc.

\section{INTRODUCTION}

Obesity and insulin resistance are associated with cardiovascular risk factors including altered levels of inflammatory markers and adipocytokines (1). The current view of adipose tissue is that of an active secretory organ, sending out and responding to signals that modulate appetite, insulin sensitivity, energy expenditure, inflammation, and immunity.

Adipocytokines are proteins mainly produced by adipocytes (2). These molecules have been shown to be involved in the pathogenesis of the metabolic syndrome and cardiovascular disease. Adiponectin is an adipocyte-derived collagen-like protein identified through an extensive search of adipose tissue. Hypoadiponectinemia increased risk of coronary artery disease together with the presence of multiple risk factors, indicating that adiponectin is a key factor of the metabolic syndrome (3). Leptin is a $16-\mathrm{kDa}$ protein secreted primarily from adipocytes. Leptin suppresses food intake and increases energy expenditure by enhancing thermogenesis and metabolic rate. Recent reports suggest that leptin contributes to atherosclerosis and cardiovascular disease in obese patients (4). Resistin is a $12.5-\mathrm{kDa}$, cysteine-rich protein identified by screening ofthe genes that are induced during the differentiation of the adipocytes. Thus, the role of resistin in linking human obesity with type 2 diabetes mellitus is questionable $(5,6)$.

Individuals with congenital generalized lipodystrophy, characterized by almost complete absence of body fat, have leptin levels seven- to tenfold less than healthy controls. However, leptin concentrations vary in partial lipodystrophy syndromes characterized by loss of adipose tissue from subcutaneous depots (7). When partial lipodystrophy is associated with an overall

\footnotetext{
*Correspondence to: Daniel A. de Luis, Centro de Investigacion en Endocrinologia y Nutricion Clinica (I.E.N), Unit of Investigation Hospital Universitario Rio Hortega, C/los perales 16, Simancas, Valladolid 47130, Spain. E-mail: dadluis@yahoo.es
}

Received 29 September 2011; Accepted 5 May 2012

DOI 10.1002/jcla.21528

Published online in Wiley Online Library (wileyonlinelibrary.com). 
reduction in fat mass, leptin levels are low (8), but leptin levels may be normal in individuals with partial lipodystrophy who have overall fat mass similar to healthy controls (9). Adiponectin levels are inversely related to adipose tissue mass (10). Patients with anorexia nervosa have higher adiponectin levels compared with controls (11). However, in lipodystrophy syndromes, including HIV lipodystrophy, adiponectin levels have been found to be relatively low despite the lower fat mass (12), suggesting that adiponectin does not retain its normal inverse relationship with fat mass in lipodystrophy and a lack of association of circulating resistin levels with fat distribution has been detected (13).

Although in vitro data suggest that sc adipocytes make more resistin, leptin, and adiponectin than visceral adipocytes (14) and given that subcutaneous adipose tissue (SAT) accounts for approximately $85-90 \%$ of adipose tissue in lean individuals (15), SAT may produce the majority of circulating adipokines. The syndrome of lipoatrophy in HIV infection is frequent. Thus, there are quantitative changes in body fat in HIV-infected patients exposed to antiretroviral (ARV) therapy (16). These changes in adipose tissue could modify circulating adipokines levels and influence cardiovascular risk factors.

The aim was to examine the relationship of fat distributions, measured by dual-energy X-ray absorptiometry (DEXA), with adipokines concentrations in HIV-infected patients exposed to ARV therapy. These data could be useful as cardiovascular predictor factors of HIV-infected patients.

\section{PATIENT AND METHODS}

\section{Patients}

This was a cross-sectional analysis of $36 \mathrm{HIV}$-infected patients. Patients between 30 and 60 years of age with HIV infection without evidence of lipodistrophy syndrome and diabetes mellitus were eligible for enrolment if they met the following criteria: a confirmed diagnosis of HIV infection, absence of chronic febrile illness, absence of severe gastrointestinal symptoms (diarrhea for $>30$ days or $>$ three times/day), adequate liver function, and normal kidney function. All patients gave informed consent before enrolment and remained under routine treatment (highly active antiretroviral therapy [HAART]), a protease inhibitor containing regimen with three agents, for HIV infection during the study and in previous 3 months.

\section{Biochemical Parameters}

Basal blood sampling was performed for determinations of glucose, lipid profile, insulin level, homeosta- sis model assessment (HOMA) index, and circulating adipokines (adiponectin, leptin, and resistin).

Serum total cholesterol and triglyceride concentrations were determined by enzymatic colorimetric assay (Technicon Instruments, Ltd., New York, NY), while highdensity lipoprotein (HDL) cholesterol was determined enzymatically in the supernatant after precipitation of other lipoproteins with dextran sulfate-magnesium. Lowdensity lipoprotein (LDL) cholesterol was calculated using Friedewald formula. Plasma glucose levels were determined by using an automated glucose oxidase method (Glucose analyser 2, Beckman Instruments, Fullerton, CA). Insulin was measured by enzymatic colorimetry (Insulin, WAKO Pure-Chemical Industries, Osaka, Japan) and the HOMA for insulin sensitivity was calculated using these values (17).

Resistin was measured by ELISA (Biovendor Laboratory, Inc., Brno, Czech Republic) with a sensitivity of $0.2 \mathrm{ng} / \mathrm{ml}$ and a normal range of 4-12 $\mathrm{ng} / \mathrm{ml}$. Leptin was measured by ELISA (Diagnostic Systems Laboratories, Inc., Webster, TX) with a sensitivity of $0.05 \mathrm{ng} / \mathrm{ml}$ and a normal range of 10-100 ng/ml. Adiponectin was measured by ELISA (R\&D systems, Inc., Minneapolis, MN) with a sensitivity of $0.246 \mathrm{ng} / \mathrm{ml}$ and a normal range of 865-21,424 ng/ml. We also measured CD4 counts (LabCorp, Uniondale, NY) and HIV viral loads (LabCorp); the minimum detection limit was 50 copies $/ \mathrm{ml}$.

\section{Weight and Anthropometric Data}

Body weight was measured to an accuracy of $0.1 \mathrm{~kg}$ and body mass index was computed as body weight $/\left(\right.$ height $\left.^{2}\right)$. DEXA (Prodigy, PRIMO8.0, GE Medical Systems, Madison, WI) was used to measure body composition, using the software analysis (Encore version 12.3, Madison, WI). Using these methods, we quantified adipose tissue volume in legs, arms, abdominal area, and trunk (chest and back). The abdominal region of interest was defined manually by adjusting the lines between upper L1 and lower L4 to calculate abdominal fat mass.

\section{Statistical Analysis}

Sample size was calculated to detect differences over $4 \%$ in fat mass between adipokine groups with $90 \%$ power and $5 \%$ significance $(n=36)$. The results were expressed as mean \pm standard deviation. The distribution of variables was analyzed with Kolmogorov-Smirnov test. Patients were divided into two groups by median adiponectin, leptin, and resistin values. Quantitative variables with a normal distribution were analyzed with a two-tailed paired Student's $t$-test. Nonparametric variables were analyzed with the Friedman and Wilcoxon tests. Qualitative variables were analyzed with the chi-square test, with 
TABLE 1. Anthropometrical and Biochemical Characteristics of Patients With HIV (Mean \pm SD)

\begin{tabular}{lc}
\hline & Group \\
Characteristics & $N=36$ \\
\hline Sex (M/F) & $10 / 26$ \\
Age (year) & $44.8 \pm 9.8$ \\
Weight (kg) & $69.3 \pm 17.1$ \\
Body mass index & $24.57 \pm 5.1$ \\
LL fat mass (kg) & $10.6 \pm 3.2$ \\
RL fat mass (kg) & $10.5 \pm 3.1$ \\
LA fat mass (kg) & $3.8 \pm 1.2$ \\
RA fat mass (kg) & $3.9 \pm 1.3$ \\
Trunk fat mass (kg) & $35.8 \pm 8.6$ \\
Fat abdominal mass (kg) & $5.6 \pm 1.6$ \\
Waist circumference & $89.2 \pm 11.9$ \\
Waist to hip ratio & $0.91 \pm 0.08$ \\
Systolic BP (mmHg) & $131.0 \pm 20.3$ \\
Diastolic BP (mmHg) & $88.7 \pm 19.5$ \\
Glucose (mg/dl) & $97.1 \pm 11.6$ \\
Total ch. (mg/dl) & $211.6 \pm 52.1$ \\
LDL-ch. (mg/dl) & $133.3 \pm 50.5$ \\
HDL-ch. (mg/dl) & $49.2 \pm 13.9$ \\
TG (mg/dl) & $189.9 \pm 53.8$ \\
Insulin (mUI/l) & $14.4 \pm 7.8$ \\
HOMA & $3.6 \pm 4.8$ \\
Adiponectin (ug/ml) & $4521.3 \pm 2,213.2$ \\
Resistin (ng/ml) & $6.3 \pm 3.3$ \\
Leptin (ng/ml) & $4.6 \pm 3.6$ \\
CD4 cell count (cells/ml) & $542.4 \pm 276.1$ \\
HIV RNA levels (copies/ml) & $8829.1 \pm 21.079 .3$ \\
\hline
\end{tabular}

M, male; F, female; BP, blood pressure; LDL-ch., low-density lipoprotein cholesterol; HDL-ch., high-density lipoprotein cholesterol; TG, triglycerides; HOMA, homeostasis model assessment; (LL, left leg; RL, right leg; LA, left arm; RA, right arm determined by DEXA).

Variables with nonparametric distribution: triglycerides, adiponectin, resistin leptin CD4 cell count, HIV RNA Levels.

Yates correction as necessary, and Fisher's test. Correlation analysis was performed with Pearson and Spearman tests. A multiple regression model (step by step) was used to study the dependent variable adiponectin (model 1), leptin (model 2), and resistin (model 3). A $P$-value less than 0.05 was considered statistically significant.

\section{RESULTS}

The mean age was $44.8 \pm 9.8$ years and the mean body mass index (BMI) was $24.5 \pm 5.1$. Baseline anthropometrical and biochemical characteristics of patients were presented in Table 1; the average value of adiponectin, leptin, and resistin was 4,521.3 $\pm 2,213.2 \mu \mathrm{g} / \mathrm{ml}, 4.6 \pm$ $3.6 \mathrm{ng} / \mathrm{ml}$, and $6.3 \pm 3.3 \mathrm{ng} / \mathrm{ml}$, respectively.

Patients were divided into two groups-Group I and II-by median of adipokine levels. The value of adiponectin, leptin, and resistin was 4,231.2 $\mu \mathrm{g} / \mathrm{ml}, 3.62$ $\mathrm{ng} / \mathrm{ml}$, and $5.11 \mathrm{ng} / \mathrm{ml}$, respectively in group I (patients with the low values) and patients with high values of adiponectin, leptin, and resistin were in group II (patients with the high values). Tables 2 and 3 show the statistical differences between both groups in terms of anthropometrical and biochemical parameters. For adiponectin, patients in the group I have higher levels of waist circumference, trunk abdominal mass, waist to hip ratio, glucose, insulin, and HOMA but lower levels of HDL cholesterol than the group II. For leptin, patients in the group II have higher levels of body mass index, weight, waist to hip ratio than the group I. For resistin, no differences were detected between groups. HIV RNA levels were same between adipokine groups.

Correlation (Table 4) analysis showed a significant correlation among adiponectin levels and the next independent variables; left arm fat mass, right arm fat mass, waist circumference, waist to hip ratio, HDL cholesterol, insulin, and HOMA. A significant correlation was detected among leptin levels and the next independent variables; BMI, weight, left leg fat mass, right leg fat mass, left arm fat mass, right arm fat mass, waist circumference. Circulating resistin was not correlated with biochemical or anthropometrical parameters.

\section{Multivariate Analysis}

In the multivariate analysis with age-, weight-, sexadjusted basal adiponectin concentration as a dependent variable (model 1) and other univariate variables related with adiponectin as independent variables, waist to hip ratio and abdominal fat area remained as independent predictors in the model $(F=5.1 ; P<0.05)$, with an inverse correlation. Adiponectin concentration decreases 5,541.2 $\mu \mathrm{g} / \mathrm{ml}$ (CI 95\%: 8,071.9-3,029.1) for each unit of waist to hip ratio and decreases $561.9 \mathrm{ng} / \mathrm{ml}$ (CI 95\%: 918.2-213.4) for each kilogram of fat mass of abdominal area.

In the multivariate analysis with age-, weight-, sexadjusted basal leptin concentration as a dependent variable and other univariate variables related with leptin as independent variables, waist circumference remained as an independent predictor in the model $(F=6.3 ; P<0.05)$, with a direct correlation. Leptin concentration increases $0.067 \mathrm{ng} / \mathrm{ml}$ (CI 95\%: 0.001-0.12) for each centimeter of waist circumference.

In the multivariate analysis with age-, weight-, sexadjusted basal resistin concentration as a dependent variable and other univariate variables related with resistin as independent variables, no independent variables remained as predictors in the model.

\section{DISCUSSION}

In this study of adiposity and adipokine levels, there were some interesting findings. As expected, weight and 
TABLE 2. Anthropometric Parameters by Median Group of Leptin, Adiponectin, and Resistin (Mean \pm SD)

\begin{tabular}{|c|c|c|c|c|c|c|}
\hline \multirow[b]{2}{*}{ Characteristics } & \multicolumn{2}{|c|}{ Adiponectin groups } & \multicolumn{2}{|c|}{ Leptin groups } & \multicolumn{2}{|c|}{ Resistin groups } \\
\hline & Low & High & Low & High & Low & High \\
\hline $\operatorname{Sex}(M / F)$ & $5 / 13$ & $5 / 13$ & $4 / 14$ & $6 / 12$ & $6 / 12$ & $4 / 14$ \\
\hline Age & $45.7 \pm 4.1$ & $43.7 \pm 5.2$ & $45.9 \pm 4.6$ & $43.5 \pm 5.3$ & $45.8 \pm 7.2$ & $43.4 \pm 12.1$ \\
\hline BMI & $24.8 \pm 5.2$ & $24.5 \pm 5.3$ & $23.2 \pm 4.6$ & $26.2 \pm 5.3^{*}$ & $23.9 \pm 5.2$ & $25.4 \pm 5.1$ \\
\hline Weight (kg) & $71.9 \pm 16.9$ & $67.6 \pm 16.6$ & $67.1 \pm 13.3$ & $72.6 \pm 17.6^{*}$ & $69.1 \pm 18.1$ & $70.5 \pm 17.6$ \\
\hline LL fat mass (kg) & $10.3 \pm 2.6$ & $11.2 \pm 3.6$ & $10.3 \pm 3.2$ & $11.2 \pm 3.7$ & $10.6 \pm 2.6$ & $11.2 \pm 3.6$ \\
\hline RL fat mass (kg) & $10.4 \pm 2.7$ & $10.9 \pm 3.4$ & $10.2 \pm 2.3$ & $11.1 \pm 3.6$ & $10.3 \pm 2.9$ & $10.9 \pm 4.0$ \\
\hline LA fat mass (kg) & $4.2 \pm 1.0$ & $3.8 \pm 1.6$ & $3.8 \pm 0.8$ & $4.2 \pm 1.6$ & $3.9 \pm 0.8$ & $4.1 \pm 3.3$ \\
\hline RA fat mass (kg) & $4.1 \pm 1.1$ & $3.7 \pm 1.4$ & $3.7 \pm 0.7$ & $4.1 \pm 1.6$ & $3.7 \pm 0.6$ & $4.0 \pm 1.6$ \\
\hline Trunk fat mass (kg) & $38.4 \pm 8.4$ & $33.6 \pm 8.5$ & $34.6 \pm 7.5$ & $37.3 \pm 9.6$ & $34.7 \pm 7.5$ & $37.5 \pm 9.9$ \\
\hline Fat abdominal mass (kg) & $6.1 \pm 1.5$ & $5.1 \pm 1.6^{*}$ & $5.4 \pm 1.5$ & $5.8 \pm 1.5$ & $5.4 \pm 1.5$ & $5.9 \pm 1.7$ \\
\hline Waist circumference & $91.7 \pm 9.8$ & $86.5 \pm 13.9^{*}$ & $86.9 \pm 11.1$ & $91.7 \pm 12.6^{*}$ & $88.6 \pm 21.1$ & $89.7 \pm 18.8$ \\
\hline Waist to hip ratio & $0.96 \pm 0.1$ & $0.86 \pm 0.09^{*}$ & $0.91 \pm 0.1$ & $0.91 \pm 0.1$ & $0.91 \pm 0.1$ & $0.92 \pm 0.1$ \\
\hline Systolic BP (mmHg) & $125.6 \pm 17.6$ & $133.7 \pm 22.5$ & $130 \pm 16.3$ & $129.9 \pm 24.3$ & $120.7 \pm 17.3$ & $128.5 \pm 19.7$ \\
\hline Diastolic BP (mmHg) & $78.4 \pm 13.8$ & $83.6 \pm 14.8$ & $87.7 \pm 11.7$ & $88.6 \pm 26.1$ & $86.8 \pm 21.1$ & $89.8 \pm 14.2$ \\
\hline
\end{tabular}

M, male; F, female; BMI, body mass index; BP, blood pressure; (LL, left leg; RL, right leg; LA, left arm; RA, right arm; V, visceral; S, subcutaneous determined by DEXA).

${ }^{*}$ Statistical differences in each adipokine median group $(P<0.05)$.

regional adiposity were positively associated with leptin levels, suggesting that adiposity remains the major determinant of leptin levels in HIV infection (18). Previous studies of leptin in HIV-infected patients have also found that leptin levels were proportional to total body fat (19). All these data suggest that leptin levels reflect total adiposity in HIV patients.

The data on adiponectin are more contradictory. In our patients, only regional adiposity (arms and abdominal fat mass) was significantly and negatively correlated with adiponectin levels, without correlation with weight or BMI. In control patients, abdominal subcutaneous tissue was found to be negatively correlated with adiponectin concentrations in Hispanics and African-Americans in univariate analysis. However, after multivariate analysis, abdominal SAT was a positive correlate of adiponectin (20). Nevertheless, in HIV-infected patients, the normal relationships between adiponectin concentration and SAT appear to be lost or reverse (21). In other study, in HIV-infected subjects there was no association between total adiposity and adiponectin, whereas adiponectin was positively correlated with both abdominal SAT and extremity (22). Other studies have found a positive correlation between extremity fat and adiponectin concentration (21). Our data show that the negative relationship between local adiposity (arms) and adiponectin disappeared in multivariate analysis, whereas central adiposity markers (waist to hip circumference and

TABLE 3. Biochemical Parameters by Median Group of Leptin, Adiponectin, and Resistin (mean \pm SD)

\begin{tabular}{|c|c|c|c|c|c|c|}
\hline \multirow[b]{2}{*}{ Characteristics } & \multicolumn{2}{|c|}{ Adiponectin groups } & \multicolumn{2}{|c|}{ Leptin groups } & \multicolumn{2}{|c|}{ Resistin groups } \\
\hline & Low & High & Low & High & Low & High \\
\hline Glucose (mg/dl) & $100.3 \pm 9.6$ & $94.2 \pm 13.1^{*}$ & $98.5 \pm 10.8$ & $96.1 \pm 10.4$ & $95.9 \pm 11.4$ & $98.7 \pm 12.2$ \\
\hline Total ch. (mg/dl) & $215.8 \pm 60$ & $205.3 \pm 44$ & $204.5 \pm 45.9$ & $217.4 \pm 60.8$ & $220.8 \pm 53.9$ & $200.4 \pm 51.1$ \\
\hline LDL-ch. (mg/dl) & $136.2 \pm 63$ & $128.9 \pm 35$ & $128.4 \pm 36.1$ & $137.1 \pm 63.4$ & $140.7 \pm 56$ & $124.4 \pm 44.9$ \\
\hline HDL-ch. (mg/dl) & $44.6 \pm 11.9$ & $53.2 \pm 14.9^{*}$ & $47.8 \pm 9.2$ & $49.81 \pm 17.8$ & $51.5 \pm 14.6$ & $45.9 \pm 13.1$ \\
\hline TG (mg/dl) & $143.4 \pm 60.2$ & $115.5 \pm 45.3$ & $138.3 \pm 61.8$ & $140.1 \pm 59.7$ & $126.9 \pm 51.8$ & $148.1 \pm 59.7$ \\
\hline Insulin (mUI/l) & $19.6 \pm 13.3$ & $8.5 \pm 4.5^{*}$ & $10.5 \pm 6.3$ & $18.4 \pm 24.8$ & $14.6 \pm 9.3$ & $10.7 \pm 4.8$ \\
\hline HOMA & $5.1 \pm 6.3$ & $3.9 \pm 0.7^{*}$ & $2.5 \pm 1.5$ & $4.7 \pm 6.7$ & $4.4 \pm 6.5$ & $2.7 \pm 1.7$ \\
\hline Adiponectin (ng/ml) & $2.8 \pm 0.6$ & $6.3 \pm 1.8^{*}$ & $4.2 \pm 1.8$ & $4.8 \pm 2.5$ & $4.2 \pm 1.9$ & $4.8 \pm 2.4$ \\
\hline Resistin (ng/ml) & $6.4 \pm 3.7$ & $6.1 \pm 2.6$ & $6.3 \pm 3.8$ & $6.2 \pm 2.6$ & $3.8 \pm 0.9$ & $8.8 \pm 1.5^{*}$ \\
\hline Leptin $(\mathrm{ng} / \mathrm{ml})$ & $3.5 \pm 1.5$ & $5.7 \pm 4.8$ & $2.5 \pm 0.8$ & $6.7 \pm 4.1^{*}$ & $3.7 \pm 1.9$ & $5.4 \pm 4.7$ \\
\hline CD4 cell count $($ cells $/ \mathrm{ml})$ & $603 \pm 273$ & $482 \pm 277$ & $501 \pm 210$ & $574 \pm 337$ & $562 \pm 297$ & $514 \pm 266$ \\
\hline
\end{tabular}

LDL-ch., low-density lipoprotein cholesterol; HDL-ch., high-density lipoprotein cholesterol, TG, triglycerides; HOMA, homeostasis model assessment.

${ }^{*}$ Statistical differences in each adipokine median group $(P<0.05)$. 
TABLE 4. Correlation Analysis Among Adipokines and Parameters

\begin{tabular}{|c|c|c|c|c|c|c|}
\hline \multirow[b]{2}{*}{ Characteristics } & \multicolumn{2}{|c|}{ Adiponectin levels } & \multicolumn{2}{|c|}{ Leptin levels } & \multicolumn{2}{|c|}{ Resistin levels } \\
\hline & $r$ & $P$ & $r$ & $P$ & $r$ & $P$ \\
\hline BMI & 0.10 & 0.74 & 0.48 & 0.01 & 0.10 & 0.45 \\
\hline Weight (kg) & 0.20 & 0.78 & 0.49 & 0.02 & 0.15 & 0.23 \\
\hline LL fat mass $(\mathrm{kg})$ & 0.05 & 0.91 & 0.73 & 0.001 & 0.16 & 0.19 \\
\hline RL fat mass (kg) & 0.11 & 0.18 & 0.74 & 0.001 & 0.09 & 0.56 \\
\hline LA fat mass (kg) & -0.36 & 0.04 & 0.83 & 0.001 & 0.11 & 0.48 \\
\hline RA fat mass $(\mathrm{kg})$ & -0.37 & 0.04 & 0.84 & 0.001 & 0.20 & 0.23 \\
\hline Fat abdominal mass (kg) & -0.47 & 0.009 & 0.67 & 0.005 & 0.08 & 0.80 \\
\hline Waist circumference & -0.46 & 0.013 & 0.57 & 0.001 & 0.19 & 0.28 \\
\hline Waist to hip ratio & -0.69 & 0.0001 & 0.12 & 0.23 & 0.20 & 0.17 \\
\hline HDL-ch. (mg/dl) & 0.37 & 0.026 & 0.14 & 0.34 & 0.11 & 0.45 \\
\hline Insulin $(\mathrm{mUI} / \mathrm{l})$ & -0.33 & 0.04 & 0.27 & 0.10 & 0.16 & 0.15 \\
\hline HOMA & -0.32 & 0.04 & 0.28 & 0.16 & 0.20 & 0.11 \\
\hline
\end{tabular}

(LL, left leg; RL, right leg; LA, left arm; RA, right arm determined by DEXA); BMI, body mass index; HDL-ch., high-density lipoprotein cholesterol; HOMA, homeostasis model assessment.

abdominal fat mass) were independent predictors of adiponectin levels.

It is easy to explain a negative correlation of abdominal fat mass and adiponectin. Our results demonstrate that adiponectin is significantly correlated with insulin resistance and HDL in HIV-infected patients, as found in the earlier studies (22). In the general population, there is also an inverse correlation between abdominal adiposity and adiponectin levels. In our study, this normal negative correlation between visceral adiposity and adiponectin was maintained too. Other measures of central adiposity (waist circumference and waist to hip ratio) have also been shown to be inversely correlated with adiponectin levels in our patients and in several studies of HIV-infected patients $(9,12,21)$. Adiponectin is thought to contribute to the regulation of insulin sensitivity (23). HOMA provides a powerful index of insulin resistance in epidemiological studies (24). Adiponectin and HOMA thus represent two different aspects of insulin resistance with opposite relations to this condition. Adiponectin accounts for approximately $0.02 \%$ of total plasma protein in humans, and its concentration is inversely associated with the risk of type 2 diabetes (25) and obesity (26). However, it is difficult to explain a positive correlation between SAT and adiponectin levels in HIV-infected patients in other studies $(22,23)$. One hypothesis suggests that the remaining SAT in HIVinfected patients with lipoatrophy is dysfunctional rather than simply reduced in size, because if the only finding were reduction in adipose tissue, adiponectin levels should be higher with less body fat, as is seen in patients with anorexia nervosa (11). However, other forms of partial lipodystrophy are also associated with low adiponectin concentrations. In familial partial lipodystrophy due to dominant-negative mutations in the peroxisome prolifer- ators activated receptor gamma or lamin a7c mutations, adiponectin levels are low with lower total fat mass (27). These findings support the concept that low adiponectin concentrations in HIV-infected patients with low levels of subcutaneous fat mass are due to lipodystrophy and low levels of fat without loss of fat cells, as in anorexia nervosa, had high levels of adiponectin (11). Perhaps, the right hypothesis is that some cases of lipodystrophies are characterized not only by decreased fat but also by loss or dysfunctioning of adipocytes.

Finally, resistin is not related with anthropometric or biochemical variables in our study, it is unlikely to play a role in the insulin resistance or fat distribution of HIVinfected patients, as indicated by Barb et al. (13).

There are few limitations of our study. First, a crosssectional design cannot prove causality between anthropometric parameters and adipokine levels. Second, because of the lack of in vivo adipose tissue study, it was not possible to determine whether adiponectin associations are due to decreased adipocyte differentiation, decreased adipose cell number, or reduced hormone expression in adipose tissue. Third, the small sample size (error type II) did not allow excluding new unknown relationships. Finally, our work shows relations with peripheral adipokine levels, and perhaps gene expression in SAT must be a more potent predictor of these associations $(28,29)$ and new molecules could be evaluated as the sterol-regulatoryelement-binding-protein-1 (SREBP1).

In conclusion, in our HIV-infected patients, leptin levels appear to be primarily determined by total adiposity and waist circumference as central adiposity marker after multivariate analysis. Central adiposity had the expected inverse association with adiponectin levels as shown in multivariate analysis with the independent predictors 
(waist circumference, waist to hip ratio, and abdominal fat mass).

\section{CONFLICT OF INTEREST}

There is no conflict of interest that could be perceived as prejudicing the impartiality of the research reported.

\section{FUNDING}

This research did not receive any specific grant from any funding agency in the public, commercial or not-for-profit sector.

\section{AUTHOR CONTRIBUTIONS}

D. A. de Luis, P. Bachiller, J. M. Eiros Bouza realized design and statistical of the study. T. Palacios, O. Izaola, and B. de la Fuente realized nutritional evaluation. R. Conde realized biochemical studies.

\section{REFERENCES}

1. Fantuzzi G. Adipose tissue, adipokines, and inflammation. J Allergy Clin Immunol 2005;115:911-919.

2. Matsuda M, Shimomura I, Sata M. Role of adiponectin in preventing vascular stenosis. The missing link of adipo-vascular axis. J Biol Chem 2002;277:37487-37491.

3. Kumada M, Kihara S, Sumitsuji S. Association of hypoadiponectinemia with coronary artery disease in men. Arterioscler Thromb Vasc Biol 2003;23:85-89.

4. Shimomoura I, Hammer RE, Ikemoto S. Leptin reverses insulin resitance and diabetes mellitus in mice with congenital lipodystrophy. Nature 1999;401:73-76.

5. Steppan CM, Bailey ST, Bhat S. The hormone resistin links obesity to diabetes. Nature 2001;409:307-312.

6. de Luis DA, Sagrado MG, Conde R, et al. Relation of resistin levels with cardiovascular risk factors, insulin resistance and inflammation in naive diabetes obese patients. Diabetes Res Clin Pract 2010;89:110-114.

7. Wong SP, Huda M, English P, et al. Adipokines and the insulin resistance syndrome in familial partial lipodystrophy caused by a mutation in lamin A/C. Diabetologia 2005;48:2641-2649.

8. Hegele RA, Kraw ME, Ban MR, Miskie BA, Huff MW, Cao H. Elevated serum $\mathrm{C}$-reactive protein and free fatty acids among nondiabetic carriers of missense mutations in the gene encoding lamin $\mathrm{A} / \mathrm{C}$ (LMNA) with partial lipodystrophy. Arterioscler Thromb Vasc Biol 2003;23:111-116.

9. Kosmiski L, Kuritzkes D, Lichtenstein K, Eckel R. Adipocytederived hormone levels in HIV lipodystrophy. Antivir Ther 2003;8:9-15.

10. Arita $\mathrm{Y}$, Kihara S, Ouchi N, et al. Paradoxical decrease of an adipose-specific protein, adiponectin, in obesity. Biochem Biophys Res Commun 1999;257:79-83.

11. Delporte ML, Brichard SM, Hermans MP, Beguin C, Lambert M. Hyperadiponectinaemia in anorexia nervosa. Clin Endocrinol 2003;58:22-29.

12. Sweeney LL, Brennan AM, Mantzoros CS. The role of adipokines in relation to HIV lipodystrophy. AIDS 2007;21:895-904.
13. Barb D, Wadhwa S, Kratzsch J, et al. Circulating resistin levels are not associated with fat redistribution, insulin resistance or metabolic profile in patients with the highly active antiretroviral therapy induced metabolic syndrome. J Clin Endocrinol Metab 2005;5324-5328.

14. Lihn AS, Bruun JM, He G, Pedersen SB, Jensen PF, Richelsen B. Lower expression of adiponectin mRNA in visceral adipose tissue in lean and obese subjects. Mol Cell Endocrinol 2007;30:915.

15. Machann J, Thamer C, Schnoedt B, et al. Standardized assessment of whole body adipose tissue topography by MRI. J Magn Reson Imaging 2005;21:455-462.

16. Tien PC, Benson C, Zolopa AR, Sidney S, Osmond D, Grunfeld C. Study of fat redistribution and metabolic change in HIV infection (FRAM). Fat distribution in women with HIV infection. J Acquir Immune Defic Syndr 2006; 42:562-571.

17. Mathews DR, Hosker JP, Rudenski AS, Naylor BA, Treacher DF. Homeostasis model assessment: Insulin resistance and beta cell function from fasting plasma glucose and insulin concentrations in man. Diabetologia 1985;28:412-414.

18. Kosmiski LA, Bacchetti P, Kotler DP, et al. Relationship of fat distribution with adipokines in human immunodeficiency virus infection. J Clin Endocrinol Metab 2008;93:216-224.

19. Grunfeld C, Pang M, Shigenaga JK, et al. Serum leptin levels in the acquired immunodeficiency syndrome. J Clin Endocrinol Metab 1996;81:4342-4346.

20. Hanley AJG, Bowden D, Wagenknecht LE, et al. Associations of adiponectin with body fat distribution and insulin sensitivity in nondiabetic Hispanics and African-Americans. J Clin Endocrinol Metab 2007;92:2665-2671.

21. Tong Q, Sankale JL, Hadigan CM, et al. Regulation of adiponectin in human immunodeficiency virus-infected patients: Relationship to body composition and metabolic indices. J Clin Endocrinol Metab 2003;88:1559-1564.

22. Addy CL, Gavrila A, Tsiodras S, Brodovicz K, Karchmer AW, Mantzoros CS. Hypoadiponectinemia is associated with insulin resistance, hypertriglyceridemia, and fat redistribution in human immunodeficiency virus-infected patients treated with highly active antiretroviral therapy. J Clin Endocrinol Metab 2003;88:627636.

23. Yamauchi T, Kamon J, Waki H, et al. Globular adiponectin protected ob/ob mice from diabetes and ApoE-deficient mice from atherosclerosis. J Biol Chem 2003;278:2461-2468.

24. Haffner SM, Kennedy E, Gonzalez C, Stern MP, Miettinen H. A prospective analysis of the HOMA model. The Mexico City Diabetes Study. Diabetes Care 1996;19:1138-1141.

25. Li S, Shin HJ, Ding EL, van Dam RM. Adiponectin levels and risk of type 2 diabetes: A systematic review and meta-analysis. JAMA 2009;302:179-188.

26. Arita $\mathrm{Y}$, Kihara S, Ouchi N, et al. Paradoxical decrease of an adipose-specific protein, adiponectin, in obesity. Biochem Biophys Res Commun 1999;257:79-83.

27. Savage DB, Tan GD, Acerini CL, et al. Human metabolic syndrome resulting from dominant-negative mutations in the nuclear receptor peroxisome proliferators-activated receptor-gamma. Diabetes 2003;52:910-917.

28. Bastard JP, Caron M, Vidal H, et al. Association between altered expression of adipogenic factor SREBP1 in lipoatrophic adipose tissue from HIV-1-infected patients and abnormal adipocyte differentiation and insulin resistance. Lancet 2002;359(9311):10261031.

29. Giralt M, Domingo P, Guallar JP, et al. HIV-1 infection alters gene expression in adipose tissue, which contributes to HIV1/HAART-associated lipodystrophy. Antivir Ther 2006;11:729740. 